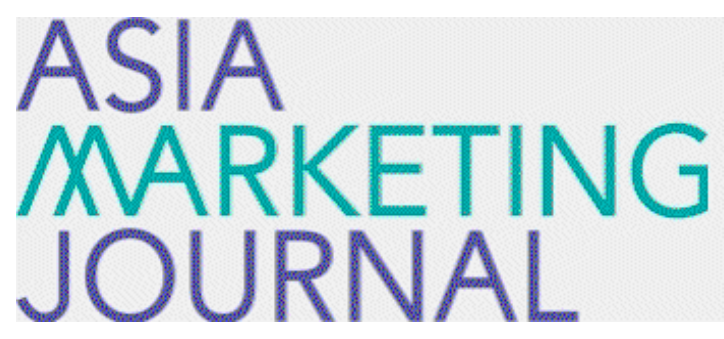

ASIA MARKETING JOURNAL

Volume 20 | Issue 1

Article 3

4-30-2018

\title{
Product Classifications Revisited with Transparency Effect
}

Jaebeom Suh

Dawn Deeter Schmelz

Taehyun Suh

Jin

Follow this and additional works at: https://amj.kma.re.kr/journal

Part of the Marketing Commons

\section{Recommended Citation}

Suh, Jaebeom; Schmelz, Dawn Deeter; Suh, Taehyun; and Jin (2018) "Product Classifications Revisited with Transparency Effect," Asia Marketing Journal: Vol. 20 : Iss. 1 , Article 3.

Available at: https://doi.org/10.15830/amj.2018.20.1.49

This Article is brought to you for free and open access by Asia Marketing Journal. It has been accepted for inclusion in Asia Marketing Journal by an authorized editor of Asia Marketing Journal. 


\title{
Product Classifications Revisited with Transparency Effect: \\ A Forgotten Link Between Consumer Research and Marketing Strategy
}

Jaebeom Suh*

Dawn Deeter-Schmelz**

Taehyun Suh***

Hyun Seung Jin****

\begin{abstract}
It is appropriate and useful to interpret some product classification schemes as buyer behavior models; such classifications permit investigations of discrepancies between classification predictions and actual buyer behavior. We review existing product classifications and identify underlying behavioral assumptions of various classification schemes that have been used in the marketing discipline for more than nine decades. Recognizing the irrelevance of existing product classifications for current products, we propose a new reclassification framework by incorporating transparency concepts. Based on this extended product classification, we highlight the potential roles of product classification study as an important link between consumer research and marketing strategy, emphasizing behavioral implications.
\end{abstract}

Key words: classification, behavior-based classification theory, transparency, marketing strategy

Ph.D. Associate Professor of Marketing Kansas State University College of Business Administration (jsuh@ksu.edu)

** Ph.D. Professor of Marketing J.J Vanier Distinguished Chair for Relational Selling and Marketing College of Business Administration (ddeeter@ksu.edu)

*** Taehyun Suh, Graduate Student School of Business Yonsei University (taesuh4@gmail.com)

**** Ph.D. Senior Lecturer School of Advertising, Marketing, and Public Relation Queensland University of Technology (QUT) Business School (hs.jin@qut.edu.au) 


\section{Introduction}

The product classification literature represents one of the oldest research traditions in marketing. Since Copeland's (1923) seminal work, substantial research has focused on the classification of products (i.e., goods and services). Researchers agree that product classifications are both strategically and theoretically relevant to marketing (e.g., Bucklin, 1963) because such classifications assist in the development of effective marketing strategies (Murphy and Enis, 1986). However, since Murphy and Enis (1986), little theoretical development exists. Furthermore, critical review and examination are lacking. Lovelock (1983) and Murphy and Enis (1986) provide extensive lists of past classification schemes; however, their "catalogues" lack a taxonomic framework and critical perspective.

More importantly, marketing researchers have not fully recognized product classification as a theoretical research domain that can potentially link consumer research and marketing strategy. For instance, the distinctions of utilitarian versus hedonic products (Yeung and Wyer, 2004), privately-consumed versus publicly-consumed products (Bearden and Etzel, 1982; Grewal et al., 2004), and luxuries versus necessities products (Grewal et al., 2004) are well-accepted product classifications in consumer behavior. The field seems to lack consensus regarding the most effective method to categorize different product categories, however.

Furthermore, the bulk of research on product classificiation is quite dated, ranging from Copeland (1923) to Murphy and Enis (1986). Yet the advent of the internet and online shopping has transformed consumer shopping behavior significantly. As such, new research is needed to examine this transformation and classify it accordingly. As a first step, a fresh reinterpretation and repositioning of the product classification literature would help stimulate new research interests in this domain, facilitating empirical tests of potential discrepancies between classification predictions and actual consumer behavior. These empirical tests, in turn, would assist practitioners in developing more effective marketing strategies.

This paper argues that behavior-predictive classifications can be consumer behavior theories with well-defined boundary conditions in terms of products. As such, the primary goal of this paper is to highlight the potential role of product classification schemes linking marketing theory and practice. We examine the practical and theoretical potential of product classification study and propose an extension of a new product classification by adding the concept of transparency to better explain behavior-based implications for product classification research. To achieve this goal, we pursue a secondary goal to develop a taxonomic framework of product classification schemes. In the following sections, we undertake a thorough examination 
of classification schemes and explore their link to theory.

\section{The Importance of Product Classifications in Marketing Strategy}

Three types of classification systems exist in the marketing literature: product-descriptive (seller-oriented), behavior-predictive (buyeroriented), and mixed-critiera (cf. Murphy and Enis, 1986). As shown in Table 1, each classification system is distinguished by the criteria employed. Product-descriptive classifications, such as Kotler's (1988) durable, non-durable, and services groups, are useful for listing product or production alternatives, but do not impart new information useful to strategy development. Behavior-predictive classifications, such as Copeland's (1923) convenience, shopping, and specialty goods, offer strategic value associated with buyer behavior information. Finally, mixed-criteria classifications like Aspinwall's (1960) gross margin, adjustment, replacement rate, time of consumption, and search time include elements of both the product and buyer-behavior. Unfortunately, although the latter addresses both product and buyer issues, the sheer number of criteria make the usefulness of mixed-criteria classifications questionable.

Of greatest interest to the present paper are behavior-predictive classifications. Two characteristics distinguish the behavior-based classification scheme. First, the behavior-based system comprises a dual, or two-step, structure. In step one, buyer behaviors are identified and classified (e.g., convenience buying behavior or search evaluation behavior). Subsequently, products associated with each type of buying behavior are identified and classified (e.g., convenience products or search goods). Second, whereas product-descriptive schemes are unambigious and deterministic, behavior-predictive schemes can only be probabilistic. A typical shopping good for most consumers can be a convenience good for other consumers, for example (Copeland, 1923). Importantly, this discrepancy between the prediction implied by the classification and the actual buying behavior invites alternative explanations. The possibility of alternative explanations of the same behavioral patterns would permit hypotheses tests. When these two characteristics (i.e., dual structure and alternative explanations) are present, the product classification becomes a set of consumer behavior hypotheses. Thus, although product classifications in general do not qualify as theory, the behavior-predictive classification systems seem to possess the potential of becoming legitimate theories. Next, we discuss the structure of behavior-based classification systems in relation to marketing practice in order to examine the role of classification "theories." 
〈Table 1〉 Types of Product Classification Systems: Benefits and Problems

\begin{tabular}{|c|c|c|c|}
\hline $\begin{array}{l}\text { Classification } \\
\text { Type }\end{array}$ & Description & Illustrative Examples & $\begin{array}{l}\text { Benefits/Problems of } \\
\text { Classification System }\end{array}$ \\
\hline $\begin{array}{l}\text { Product- } \\
\text { Descriptive } \\
\text { Classification }\end{array}$ & $\begin{array}{l}\text { Classification criteria } \\
\text { related directly to } \\
\text { product. E.g., product } \\
\text { characteristics, } \\
\text { operation/ production } \\
\text { processes, or intended } \\
\text { use/users. }\end{array}$ & $\begin{array}{l}\text { Kotler (1988): } \\
\text { Durable, nondurable, and services } \\
\text { Lovelock (1983): } \\
\text { Nature of the service act, customer } \\
\text { relationship, customization and } \\
\text { judgment, the nature of demand and } \\
\text { supply, and method of service delivery. }\end{array}$ & $\begin{array}{l}\text { Useful for descriptive purposes, i.e., listing } \\
\text { product or production alternatives. } \\
\text { Most descriptive classifications suggest } \\
\text { reclassification possibilities through product } \\
\text { or production modifications (e.g., Bell 1986). } \\
\text { Do not impart new information beyond the } \\
\text { input information required for product } \\
\text { groupings. }\end{array}$ \\
\hline $\begin{array}{l}\text { Behavior- } \\
\text { Predictive } \\
\text { Classification }\end{array}$ & $\begin{array}{l}\text { Classification based on } \\
\text { expected patterns of } \\
\text { consumer behavior } \\
\text { relative to the product. }\end{array}$ & $\begin{array}{l}\text { Copeland (1923): } \\
\text { Convenience, shopping, and specialty } \\
\text { goods. } \\
\text { Nelson (1970, 1974): } \\
\text { Search goods, experience goods. } \\
\text { Darby and Karni (1979) } \\
\text { Credence goods. }\end{array}$ & $\begin{array}{l}\text { Strategic value associated with buyer } \\
\text { behavior information. } \\
\text { Discrepancy between classification } \\
\text { predictions and actual buyer behavior } \\
\text { permit empirical tests examining alternative } \\
\text { explanations (hypotheses). }\end{array}$ \\
\hline $\begin{array}{l}\text { Mixed- } \\
\text { Criteria } \\
\text { Classifications }\end{array}$ & $\begin{array}{l}\text { Classification based on } \\
\text { a combination of } \\
\text { product-descriptive and } \\
\text { behavior-predictive } \\
\text { approaches. }\end{array}$ & $\begin{array}{l}\text { Aspinwall (1960): } \\
\text { Gross margin, adjustment, replacement } \\
\text { rate, and time of consumption (product } \\
\text { characteristics); search time (buyer } \\
\text { behavior) } \\
\text { Miracle (1965): } \\
\text { Unit value, technical complexity } \\
\text { (product characteristics); Significance } \\
\text { of purchase to consumer, time and } \\
\text { effort spent on purchasing (buyer } \\
\text { behavior). }\end{array}$ & $\begin{array}{l}\text { Overcomes deficiencies in } \\
\text { product-descriptive and behavior-predictive } \\
\text { approaches. } \\
\text { Practical problem of identifying a } \\
\text { manageable number of meaningful criteria. } \\
\text { For example, Aspinwall's five criteria imply } \\
32 \text { different product categories. Tends to } \\
\text { result in arbitrary choices for classification } \\
\text { groups. }\end{array}$ \\
\hline
\end{tabular}

\subsection{A Link Between Theory and Practice}

The dual structure of behavior-based classification theory is shown on the left side of Figure 1. The figure shows that we develop product classification schemes on the basis of behavioral hypotheses in order to account for empirically observed behavior patterns that differ across a spectrum of products.

Overall, Figure 1 also reflects the role of 
〈Figure 1〉 Product Classification and Marketing Strategy

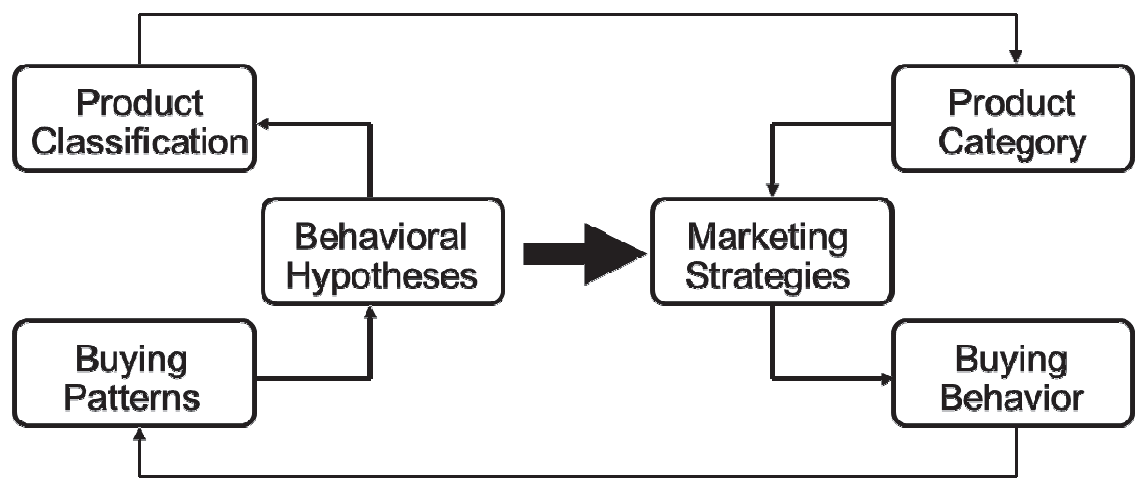

Steps in Product Classification Study
Hypothesized Marketing Reality product classification research in marketing. Behavioral hypotheses are the basis of productcategory-specific marketing strategies. The behavioral hypotheses predicts the consumer's purchase-related behavior and, more importantly, provide underlying causal explanations for such behavior. Therefore, a good classification theory helps develop effective marketing strategies which are readily applicable to a predefined set of products.

The right half of Figure 1 represents a view of marketing reality. Bucklin, pointing out that we implicitly assume that product category determines appropriate marketing strategy, raised an important question: "might not marketing strategy influence the buying patterns which are the basis for the product categories?" (1976: page 384) This reverse causation argument (i.e., strategies influence product category) can be consistent with the seemingly opposite position (i.e., strategies should be based on product category), particularly if we consider different time horizons. That is, product categories dictate the appropriate strategies in the short run, however over the long run, marketing strategies might influence consumer buying behavior and, consequently, change the product category (see Figure 1). Many marketing strategies are ultimately aimed at influencing or changing buying behavior; for example, advertising campaigns for supposedly "convenience goods" may indeed promote consumers' "shopping behavior" by emphasizing the difference across the brands. As such, product classification research plays an important role in marketing strategy development. Toward this end, we next review the history of behavior-predictive classification models emanating from the work of Copeland (1923) and, building on this earlier work, propose a new model for consideration. 


\section{Product Classifications as Behavioral Hypotheses}

Although most marketers are familiar with Copeland's (1923) behavior-predictive classification of convenience, shopping, and specialty goods, few realize that the research stream emanating from it may represent the longest lasting debate in the history of marketing research. In what follows, we review different theoretical explanations (i.e., buyer behavior assumptions) that build on Copeland's (1923) classification scheme. We, in turn, will build on this historical review to develop a model of product classification theory.

\subsection{Holton-Luck Debate (1958-1959): "Utility Maximizer"}

In 1948, the American Marketing Association (AMA) adopted Copeland's classification. AMA defined:

convenience goods as 'those consumers' goods which the consumer usually purchases frequently, immediately, and with a minimum effort." Shopping goods were defined as " . . . goods which the consumer, in the process of selection and purchase, characteristically compares on such bases as suitability, quality, price and style." Specialty goods were " ... goods on which a significant group of buyers characteristically insists and for which they are willing to make a special purchasing effort.” (Holton, 1958: 53)
In interpreting the above definition, Holton (1958, 1959) and Luck (1959) agreed that consumer shopping/comparison effort depends upon the anticipated "probable gains" from such effort. This effort is a subjective, comprehensive concept defined as "the searching cost in terms of time, money, and effort" (Holton, 1958: 54). Thus, shopping behavior (hence, the shopping good's status) is contingent upon the consumer's perception of probable gain from the search effort. Underlying this model is the assumption that consumers are utility maximizers.

For specialty goods, however, Holton (1958, 1959) and Luck (1959) disagreed. Holton (1958, 1959) argued that special purchase effort is needed for specialty goods, due to the limited size of demand and, hence, the limited availability. Luck (1959), on the other hand, hypothesized that the consumer's brand allegiance (limited number of acceptable substitutes) determines the amount of special purchase effort the consumer willingly expends to acquire the item. In sum, Holton (1958, 1959) asserts that the external market situation is the reason for the special purchase effort (hence, specialty goods), whereas Luck (1959) contends that consumer's preference is the reason. This part of Holton-Luck debate reminds us of the long-contended person-situation debate in social psychology. 
3.2 Bucklin (1963): "Problem Solver"

Bucklin (1963) identified non-shopping goods (i.e., convenience and specialty goods) as those goods for which consumers typically use stored solutions; shopping goods are those for which consumers develop new solutions. The consumer's solution is equivalent to a preference map. A product is a specialty good, if the applicable stored preference map is highly rankordered; otherwise, it is a convenience good.

Bucklin's (1963) hypotheses can be summarized as shown in Figure 2. Whether a consumer uses his or her stored solution depends on three conditions: product/brand experience, varietyseeking, and the possible changes in products or situations. In general, Bucklin (1963) understood purchase behavior as a sequential problem solving process where extensive external information search characterizes shopping goods.
The loop at the bottom of the model represents Bucklin's (1963) elaboration of Holton's (1958, 1959) hypothesis that search effort is positively related to probable gain. Bucklin postulates that "the consumer continues to shop ... so long as ... the additional satisfaction from further comparisons are at least equal to the cost of making the additional effort" (1963: 374). The economic concept of profit maximization (i.e., marginal return equals marginal cost) is applied. Not surprisingly, his hypothesis is consistent with economics of information theory (see Nelson, 1970: 313: Stigler, 1961).

\subsection{Kaish (1967): "Dissonance Minimizer”}

Based on Festinger's cognitive dissonance theory, Kaish (1967) viewed a consumer's decision making as an "anxiety-inducing activity" where the consumer's goal is to minimize the

〈Figure 2〉 Behavioral Hypotheses in Product Classification:

"Problem Soving" Model Implied by Bucklin (1963)

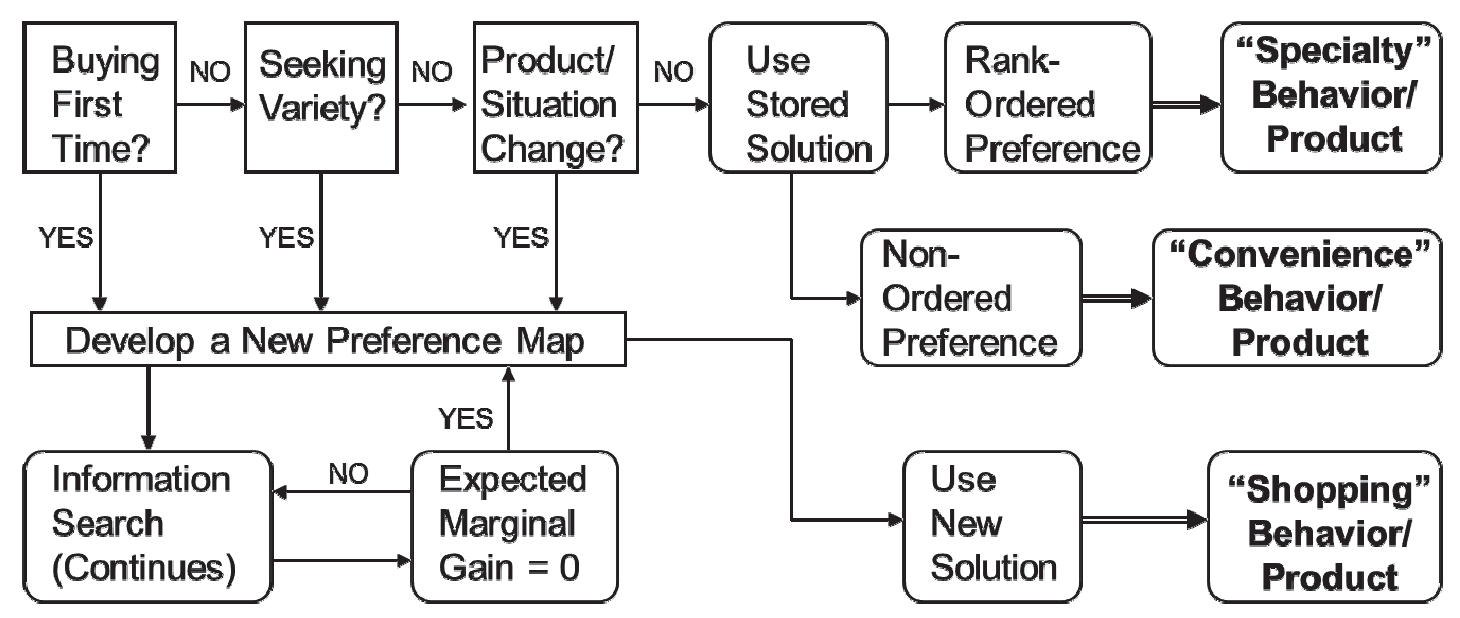


”postdecision cognitive dissonance" (1967: page 29). Hence, according to Kaish, different buying patterns result from a consumer's dissonance coping behavior.

Figure 3 captures the essence of Kaish's (1967) hypotheses. The consumer is hypothesized as posing a set of questions. Low levels of product quality heterogeneity and product importance lead to convenience buying behavior (hence, such products are convenience goods); whereas the consumer's evaluation capability and the availability of the preferred brand are hypothesized as determining whether the consumer will follow shopping behavior or specialty buying behavior.

\subsection{Murphy and Enis (1986):} "Risk Handler"

The 1986 article by Murphy and Enis is the most recent addition to the Copeland-type of product classification that uses convenience, shopping, and specialty categories. The following excerpt summarizes Murphy and Enis's (1986) classification:

These costs should be conceptualized on two independent dimensions--effort and risk. Effort is the amount of money, time, and energy the buyer is willing to expend . . . There is risk, . . . financial, psychological, physical, functional, and social. . . Four categories of product-convenience, preference, shopping, and specialty-are defined in terms of the buyer's evaluation of price. [Italicized for emphasis]

Consumer effort and risk are highest with specialty products, and lowest with convenience goods. Fundamentally, Murphy and Enis (1986) assume that consumer buying behavior (effort) differs according to the level of product risk.

〈Figure 3〉 Behavioral Hypotheses in Product Classification:

"Cognitive Dissonance" Model Implied by Kaish (1967)

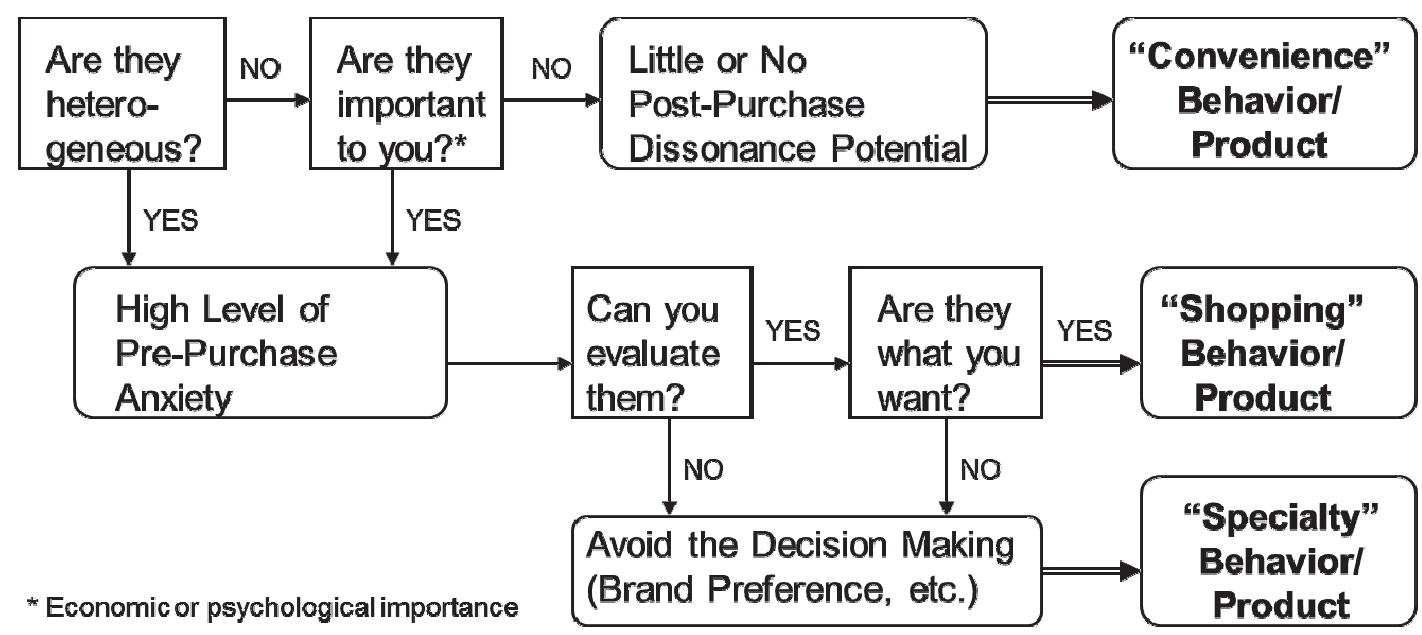


This explanation first appears to be similar to that of the classical Holton-Luck model except for an additional category, the preference product category, due to Holbrook and Howard (1977). However, in a structural sense, the Murphy and Enis (1986) classification is significantly different from the earlier work reviewed, especially from this paper's unique perspective. Specifically, Murphy and Enis's (1986) conceptualization of effort (which include both product price and time effort) is different from that of Holton (1958, 1959) and Luck (1959). Traditionally, effort did not include product price; instead, effort (excluding product price) was treated as a dependent variable (or the defining characteristics of different behavior and, hence, product category) determined by antecedent conditions (e.g., perception of probable gains). Because the classification criteria already include the amount of time spent searching (i.e., behavior), it will be tautological for Murphy and Enis (1986) to predict the associated buying behavior. As a result, their classification is descriptive in nature as it could not be interpreted as behavioral hypotheses.

Additionally, the two classifying dimensions (i.e., effort and risk) are not really independent, despite the authors' position. Such non-independence comes from the fact that the magnitude of financial risk depends on the level of product price, while the product price is a component of effort. If the product price component is prevailing in either the effort dimension, the risk dimension, or both, then their classification will approximate a unidimenisonal scheme. However, we have to emphasize that there is nothing wrong, with Murphy and Enis's (1986) interpretation and extension of the Copeland (1923) classification. As discussed earlier, multiple classification approaches are equally valid. At the same time, it should be noted that Murphy and Enis (1986) made a significant contribution by integrating the previous literature into a single cohesive framework. Most importantly, they made an important pioneering contribution by repositioning product classification as an important research domain relevant for both practitioners and academicians. The current paper can be seen as an extension of Murphy and Enis (1986).

\subsection{A Summary: Historical Evolution of Classification Hypotheses}

The preceding review of literature identified various buyer behavior assumptions or hypotheses underlying the behavior-predictive product classification systems. Although conceptually similar, it is interesting to note that the rationales for the classifications are derived from different academic disciplines. The Holton-Luck explanation (utility maximizer) is based on economics; Bucklin's (1963) problem-solver model is based on both economics and psychology; and Kaish's (1967) dissonance-minimizer explanation comes from psychology. Murphy and Enis's (1986) 
description is based on a marketing-as-socialexchange perspective, a concept originated in sociology. This theoretical diversity clearly shows the multidisciplinary nature of marketing. Further, the chronological changes reflect the historical evolution of product classification. In what follows, we discuss the (potential) role of the product classification research in the field of marketing.

\section{Product Classification Theory: Reclassification of Products through Transparency}

In the past, product classification has not been fully recognized as a theoretical research domain (e.g., Luck, 1959; Assael, 1974). We argue that behavior-predictive product classifications can be consumer behavior theories with welldefined boundary conditions. As shown in Figure 4 , product class affects both consumer behavior (consumer characteristics, situational factors, and marketing mix elements) and behavioral antecedents (e.g., affect and cognition). Consumer behavior is also directly affected by behavioral antecedents. Product class affects behavioral antecedents directly, and buying-related behavior indirectly. Market transparency, in the form of price and quality transparency, is positioned as a moderater influencing the relationship between behavioral antecedents and buying-related behavior.

A unique aspect of the suggested framework is that product class plays the key role in the theoretical structure. In many marketing studies, marketing mix elements (rather than product class) or situational factors are the beginning point of the research or the key independent variables. Consequently, little attention is given to the product class. On the other hand, our alternative framework place product as the focal independent variable. This alternative, yet complementing, framework acknowledges that, in many cases, other variables in the model (i.e., consumer characteristics, situational factors, and marketing mix variables other than product class) are not really independent from the product class. Consequently, marketing mix elements such as price and promotion are typically constrained by the product class. For example, several national brands in the product class of over-the-counter cold and flu medicines are under intense competitions and their price is strongly influenced by theire own competitors. Similarly, to a large extent, product class predicts the consumer characteristics and the purchase situations. To take advantage of such environmentally pre-existing correlations, in this approach, therefore, the association between product class and behavioral antecedents is highlighted in addition to the link betweeen the antecedents and behavior. This additional emphasis on the product-antecedent link is justified in view of the practical importance of 
product class in marketing strategy decision (Figure 1).

Murray's (1991) test of services marketing theory can be seen as an example that has generally followed the framework outlined in Figure 4. In essence, Murray (1991) hypothesized that a particular product category (i.e., services) induces a common behavioral antecedent (i.e., high level of perceived risk), which, in turn, leads to a behavior (i.e., information acquisition) that is different from that of other products. If he did not limit the products included in the study to services, Murray's (1991) study could be interpreted as part of product classification study proposed here. By doing so, we can set the boundary condition of Murray's (1991) core behavioral hypotheses in terms of product classes. From the foregoing example, it is evident that the existing approach, is no longer a viable classification model. We attempt to shed light on the relationship between produt class and behavioral antecedents to cover the base of prior literature streams.

Transparency plays a key role in Figure 4, and in fact differentiates our model from previous classification schemes that do not account for transparency. Our model addresses in greater detail the transparency effect and the necessicity to include it for present day product classifications. Specifically, we consider price and quality transparency as components of market transparency. Consumers are more informed about prices and qualities on products because of the availability of information on the internet, thereby increasing market transparency significantly. Lynch and Ariely (2000) suggest a concept of maximally transparent shopping systems with easy accessibility of (1) price and quality information and (2) across-store price comparisons information. These two

〈Figure 4〉 General Structure of Product Classification Theory

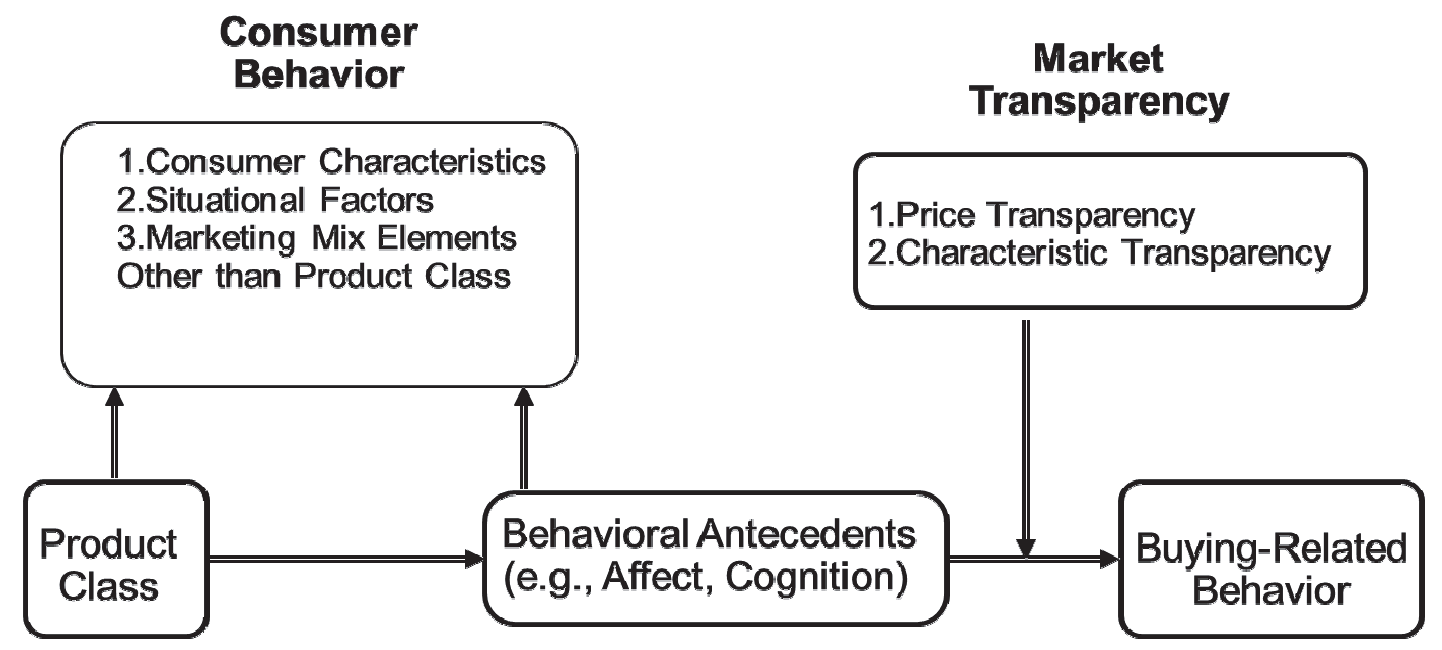

Product Classifications Revisited with Transparency Effect: A Forgotten Link Between Consumer Research and Marketing Strategy 59 
characteristics of transparent system lowers consumer's search cost significantly, and consequently will change consumer behaviors. The concept of transparent system can be naturally extended to, without much loss of generalizability, product category, product class, and entire market itself, depending how we define those entities. That said, market transparency directly affects competition among firms, which creates a favorable environment for consumers (Anderson and Renault, 1999). Thus the inclusion of transparency in product classification is warranted.

\subsection{Market Transparency}

Market transparency has been reviewed from several different, albeit related, perspectives. First, Varian (1980) showed that within a homogenous market, market transparency is imperfect. Analyzed via Nash equilibrium, he revealed that the expected profit a firm would receive decreases, as market transparency is likely to increase competition among firms. Focus on the homogenous market shifted to an open market when researchers such as Burdett and Judd (1983) or Stahl (1989) delved into consumers' tolerance for the effort behind searching. The study focused on the effects of lowering search costs and how consumers change their behavior based on search costs, which resulted in an overall increase of searches from consumers and competition between firms.
Anderson and Renault (1999) follow a similar line of study by examining the price competition between firms when consumers must search for prices and product characteristics. The authors found that as more and more consumers sought after product diversity, the time and effort spent on searching for better products increased, which resulted in a more competitive market (Anderson and Renault, 1999). Their study replicated the findings of Burdett and Judd's by confirming the increase of intense competition among firms when consumers made greater efforts to find goods increasing their overall costs to search. However, after a certain threshold of searches, the effects of heterogeneity diminishes as the prices will incrementally increase.

The need to revisit transparency in the market has increased due to the establishment of the internet. Prior to the internet, consumers had to spend a lot of time and effort to compare prices and qualities of products over a span of various markets. The information gap between the informed and uninformed consumer in the market allowed for the classic cognitive dissonance model (see Figure 3) to exist. Today, information is available easily and cheaply, thereby rendering this model obsolete. With a few clicks of the mouse, consumers have readily available price comparisons, reducing their search costs immensely (Schultz, 2005). As such, both price transparency and quality transparency warrant further discussion. 


\subsection{Price transparency}

Consumers have discrepancies in the amount of knowledge they have about the prices of products. Some are quite informed whereas others have minimal information. The information gap is evident as informed consumers know firms' prices while uninformed consumers simply have an expectation of the price, which leaves room for inaccuracy. However with the integration of the internet shopping, consumers now have access to sites that compare prices of different firms. Thus, price becomes more transparent to consumers. With improved price transparency, prices are readily observed and with only a short delay (Schultz, 2005). The internet, in particular, is the most influential agent in making market prices become more transparent. With such readily available information, the established behavioral process that consumers previously held becomes distorted. Goods that were considered shopping or specialty behavior may become convenience goods, as plentiful information is provided through third-party platforms such as Amazon. The abundant information can ease the previously felt anxiety when searching for shopping or specialty products. Increasing the transparency of prices promotes market competition, which will lead to a decrease in market prices making the decision to choose products more affordable and less risky, and consumers directly benefit from the promoted competition (Stigler, 1964;
Tirole, 1988).

\subsection{Quality Transparency}

Product quality/characteristics are not as obvious to consumers as price may be. As mentioned previously, search goods for some consumers can be experience goods for others. Because a good's characteristics can be convoluted with products such as insurance policies, internet access or mobile phones, uninformed consumers are only able to have expectations about characteristics (Schultz, 2004). Because consumers have imperfect information on the quality of products, they must revert to information like high prices implying quality. By improving quality transparency, consumers can more easily compare substitutable goods with differentiating product qaulities. Even goods within the convenience category can dip into the shopping category when the product differentiation information is easily accessible. For instance, a pack of 24 water bottles may shift from a convenience good (requires minimal information, minimal dissonance) to a shopping good when information such as "eco-friendly design," "flexibility for both carrying and recycling," etc. When goods can be successfully differentiated, the improved transparency on the consumer side acts as a shifting mechanism that guides consumers into different behavioral patterns . Improved transparency can prevent tacit collusion as well, which again allows for prices to drop, 
benefiting the consumer (Schultz, 2004). Thus, product differentiation plays an important role to create new decision boundaries as well as enable competitive markets for the consumer.

Not all platforms or markets provide full transparency of information. It is important to distinguish the different behavioral patterns when transparency is limited in contrast to when transparency is clear-cut. Low transparency information and prices is likely to follow Kaish's (1967) traditional classification because of the information discrepency between consumers and firms. However, high transparency is going to blur the classic boundaries, as the model does not account for many consumers to be highly informed. Therefore, if transparency is high for products, consumers become knowledgable and this begins to shift their behavioral patterns. Through high levels of transparency, products that were once considered convenience products may become shopping goods or vice versa. Ultimately, the classic product classification is outdated and cannot account for the effects of transparency. Thus, we as researchers must adapt to this change as well by offering a reclassication of this cognitive process. With the reduction of search costs, it becomes more difficult to categorize products under the classic product classification schemes of convenience, shopping, and specialty product. It is obvious that product classification needs a reclassification scheme and we contend the inclusion of market transparency as a key moderator in the product classification theory, considering the advent and power of internet in the marketplace.

\section{Directions for Future Research}

By recognizing classifications as potential theories, we can readily identify potential research directions. In particular, future research directions for behavior-based classification schemes are derived from the sequence presented in Figure 1. There are three basic/academic research directions: (1) developing new hypotheses that can account for the observed buying patterns; (2) testing the validity of the proposed behavioral hypotheses; and, finally, (3) classifying a wide range of products by operationalizing the existing product classifications.

Identifying Buying Patterns. There are many important dimensions of consumer behavior other than the buying effort identified by Copeland (1923). Nine decades of marketing research since Copeland have identified numerous consumer buying behavior patterns that can be used for future product classification theories. For example, the concepts of involvement, variety-seeking, or novelty-seeking have often been associated with specific product classes, although without enough theoretical or empirical justifications. Simply put, we propose to identify the boundary conditions for existing consumer 
theories in terms of product class. Because classification theories based on behavior models provide practical guidelines for marketing strategy, multiple classification theories - based on different behavior dimensions - may help fine-tune the strategy development.

Testing Behavioral Hypotheses. Despite the need for empirical verification, consumer behavior research has generally not tested these hypotheses which implicitly underly the existing classification schemes (see, for example, Bucklin, 1976). If the classification "theories" are to become true theories, we should first test and establish the validity of existing propositions. Tests of behavioral hypotheses employed in classifications need not be different from the usual theory tests except for clear expectations of productspecific effects. Various behavioral hypotheses discussed earlier in this paper can be subject to empirical tests. For instance, the shopping good's status (or shopping behavior) may stem from high levels of prepurchase cognitive dissonance (Kaish, 1967) or from the absence of pre-existing preference maps (Bucklin, 1963). Additionally, Holton-Luck debate on specialty goods could be settled empirically.

To date, little work in this area has been completed. Other than the aforementioned Murray (1991), Goldman and Johansson's (1978) test of the economics of information theory seems to be a rare example in this direction (they tested the search hypothesis on a single product class: gasoline).

Conducting Product Classifications. It appears obvious that the goals and outcomes of classification theories are empirical classifications of various products. Surprisingly, there is very little research in this direction. Nelson's (1970) product classification based on empirical data is an exception. Although classifications have been suggested along with various hypotheses, product classifications are rarely (if ever) reported especially in marketing literature.

The key question in an empirical product classificatoin study will be whether the product in question really invokes the behavioral antecedent as hypothesized (see Figure 4). An important first step in this direction would be precise operationalization of the employed constructs. A meta-analysis of empirical studies can be an alternative beginning point. Numerous experimental studies in marketing involve specific products as target objects. In the latter approach, one would be interested in the different effects of "product manipulation" on the mediating variables that conceptually precede the dependent variables.

In summary, none of the three basic research possibilities have been seriously explored. Unfortunately, therefore, any effort to derive strategic implications from the existing product classification would be a premature and precarious attempt. 


\subsection{Exploring Appropriate Strategies}

In addition to the previously mentioned research needs, researchers might also concentrate on developing new marketing strategies that take advantage of classification theories. This research corresponds to the arrow from behavioral hypotheses to marketing strategies (Figure 1). In fact, "the purpose behind the theory is to provide a guide for developing marketing strategy" (Bucklin, 1976: page 382). In this regard, we should note two important points. First, the strategic insights from classification theories will depend on the soundness and richness of the underlying behavioral hypotheses. Second, we may not be quite ready for this applied research yet, given that the product classification theories are yet to be empirically developed and tested. Therefore, our discussion focuses on the three basic research directions.

\subsection{Bring Products Back In}

As a result of such a lack of rigorous research, researchers frequently observe violations of the behavioral predictions implied by commonly accepted product classification schemes (e.g., Wilkie and Dickson, 1991). Duncan and Olshavsky state: "Limited search sometimes occurs even for so-called specialty and shopping goods and for first-time purchases" (1982: page 32). These authors suggest that, in the real world, product classification theories do not demonstrate predictive power. Why are such violations of commonly held assumptions observed? Why are empirical tests so rare? Or, more fundamentally, why do not we have product classification theories yet? We try to answer these questions in this section.

First of all, the observed inconsistencies are consequences of our misperception of product classification. Many of us do not recognize that a behavior-predeictive classification is qualitatively different from a product-descriptive classification, and that, by its construction, it cannot produce deterministic product categorization. The behaviorpredictive product classifications are hypotheses which are generally untested in the existing literature.

Second, and more important, buying behavior is influenced by personal characteristics, situational factors, and marketing mix variables in addition to the target product class, as noted by early product classification researchers (see Figures 2, 3, and 4). Generally, these variables (i.e., product, consumer, situation, and marketing mix) interact with each other in a complex manner. Omission of an important variable constitutes a misspecification error. It is naive to expect product category alone to predict buying behavior. At the same time, it is also simplistic to assume that consumer and situation variables (in the absence of product classification) are sufficient predictors of behavior. In particular, Lynch (1982) argues that identification of "background" factors that systematically interact with focal variables can enhance the external 
validity of research findings, because “... background factor treatment interactions affect estimates of the of the population 'main effect' of the treatment" (Lynch, 1982: page 228). Therefore, more valid behavioral predictions can be made when we simultaneously consider both product class and consumer/situation/ marketing variables.

Historically, marketing researchers have paid attention to consumer characteristics (e.g., expertise, enduring involvement, social status, etc.) in addition to many marketing mix variables. Similarly, situational variables have been extensively studied (e.g., effects of time pressure, music, situational involvement, information load, etc.). In contrast, not much effort has been expended on product class specific effects. As a result, we have relatively little knowledge of product effects on buying behavior.

Other things being equal, consumer research findings are more often attributed to consumer, situation, or other marketing mix variables (which supposedly are controllable) than to productinherent characteristics. Because generalization across product classes is a preferred goal of academic research, researchers tend not to be interested in product-specific effects. We have a bias against product-specific studies.

Finally, an empirical product classification study would envolve a tedious repetitive process. Ferber (1977) cautioned against a "research by convenience" practice which favors the use of student sample in consumer research; for the same reason of convenience, we might have been shying away from a rigorous examination of stimuli effects. Certainly, a comprehensive classification of products is practically an unattainable goal; however, a useful and theoretically meaningful classification can be developed if we become more sensitive to the product factor while conducting marketing research (see Lynch, 1982 for some strategies that can be applied for this purpose).

On the other hand, from a marketing manager's point of view, product class is the key variable. The current research focus on consumers is undoubtedly right; but, an equally valid proposition is that they are consumers of products. In summary, product classification is an important, yet neglected, aspect of marketing research.

\section{Concluding Comments}

Past product classifications could be classified as one of the three approaches; among them, the behavior-predictive approach seems to be the most valuable in terms of marketing strategic implications. A review of the literature reveals different consumer behavior assumptions underlying product classifications. A dual structure in product classification makes the behavior-predictive classifications qualify for hypotheses which can be empirically tested.

When we recognize product classifications as 
theories readily applicable to marketing strategies, classification research becomes a critical link between the theory and practice. However, product classification received relatively little attention by marketing researchers. This trend is due partly to our preoccupation with the generalizability of the findings across stimuli. Product class itself cannot be controlled by firms and simply given to them. In this light, product classification has a limited role for developing strategic insights, other than serving a moderator role for research purpose. That is why product classification research did not receive much attention in the past literature.

Acknowledging the paucity of research, this paper suggests a few directions for future research. Above all, a fundamental position advocated in this paper is that products are as important as consumer characteristics, situational factors, and other marketing mix variables in determining buyer behavior. Thus, products should be considered one of the primary dimensions in marketing research. Product classification research based on behavioral hypotheses is a first-step in that direction. The next step requires the understanding of the effects of transparency in the market. Transparency allows for consumers who were less informed to gain the proper information regarding a product's price and characteristics. Consumers are now able to gain information relatively easily that was not available to them prior to the internet. The decrease in search costs causes the traditional boundaries of the product classification model to become ambiguous. Goods that were considered shopping or specialty goods may become convenience goods and goods that were considered convenient may become differentiated into commodity goods. Thus, through transparency consumers become more knowledgable about the market with cheap and minimal effort which causes a change in their behavioral thinking process. Finally, It is hoped that this paper will stimulate marketing researchers' future interest in this domain with empirical research, and contribute to a revitalization of this nine-decade-old marketing research tradition.

〈Received December 28. 2017〉

〈Accepted April 16. 2018〉

\section{References}

Assael, H. (1974). Product classification and the theory of consumer behavior . Journal of the Academy of Marketing Science, 2(4), 539-552.

Anderson, S. P. and Renault, R. (1999). Pricing, product diversity, and search costs: a Bertrand-Chamberlin-diamond model. The RAND Journal of Economics, 30(4), 719735.

Aspinwall, L. V. (1961). The marketing characteristics of goods. Four Marketing Theories. Boulder, CO: University of 
Colorado, 16-21.

Bearden, W. O. and Etzel, M. J. (1982). Reference group influence on product and brand purchase decisions. Journal of Consumer Research, 9(9), 183-194.

Bell, M. L. (1986). Some strategy implications of a matrix approach to the classification of marketing goods and services. Journal of the Academy of Marketing Science, 14 (Spring), 13-20.

Bucklin, L. P. (1963). Retail strategy and the classification of consumer goods. Journal of Marketing, 27(1), 51-56.

(1976). Retrospective comment

on retail strategy and the classification of consumer goods. The Great Writings in Marketing. H. A. Thompson, ed., Plymouth, MI: The Commerce Press, 382-388.

Burdett, K. and Judd, K. L. (1983). Equilibrium price dispersion. Econometrica, 955-969.

Copeland, M. T. (1923). The relation of consumers' buying habits to marketing methods. Harvard Business Review, 1(4), 282-289.

Darby, M. R. and Karni, E. (1973). Free competition and the optimal amount of fraud. Journal of Law and Economics, 16 (4), 67-86.

Duncan, C. P. and Olshavsky, R. W. (1982). External search: the role of consumer beliefs. Journal of Marketing Research, 19 (2), 32-43.

Ferber, R. (1977). Research by convenience. Journal of Consumer Research, 4, 57-58.
Goldman, A. and Johansson, J. K. (1978). Determinants of search for low prices: an empirical assessment of the economics of information theory. Journal of Consumer Research, 5(12), 176-186.

Grewal, R., Mehta, R, and Kardes, F.R. (2004). The timing of repeat purchases of consumer durable goods: the role of functional bases of consumer attitudes. Journal of Marketing Research 2004, 41(1), 101-115.

Holbrook, M. B and Howard, J. A. (1977). Frequently purchased nondurable goods and services. Selected Aspects of Consumer Behavior. Robert Ferber, ed., Washington, DC: National Science Foundation, 189-222. Holton, R. H. (1958). The distinction between convenience goods, shopping goods, and specialty goods. Journal of Marketing, 23 (6), 53-56.

(1959). What is really meant by 'specialty' goods? Journal of Marketing, 24 (10), 64-66.

Kaish, S. (1967). Cognitive dissonance and the classification of consumer goods. Journal of Marketing, 31(10), 28-31.

Kotler, P. (1988). Marketing Management: Analysis, Planning, Implementation, and Control. 6th ed., Englewood Cliffs, NJ: Prentice Hall.

Lovelock, C. H. (1983). Classifying services to gain strategic marketing insights. Journal of Marketing, 47(Summer), 9-20.

Luck, D. J. (1959). On the nature of specialty 
goods. Journal of Marketing, 24(6), 61-64. Lynch, J. G. Jr. (1982). On the external validity of experiments in consumer research. Journal of Consumer Research, 9(12), 225-239.

Lynch, J. G. Jr. and Ariely, D. (2000). Wine online: search costs affect competition on price, quality, and distribution. Marketing Science, 19(1), 83-103.

Miracle, G. E. (1965). Product characteristics and marketing strategy. Journal of Marketing, 29(1), 18-24.

Murphy, P. E. and Enis, B. M. (1986). Classifying products strategically. Journal of Marketing, 50(6), 24-42.

Murray, K. B. (1991). A test of services marketing theory: consumer information acquisition activities. Journal of Marketing, 55(1), 1025.

Nelson, P. (1970). Information and consumer behavior. Journal of Political Economy, 78 (2), 311-29.

(1974). Advertising as information. Journal of Political Economy, 82(4), 72954.
Schultz, C. (2004). Market transparency and product differentiation. Economics Letters, 83(2), 173-178. (2005). Transparency on the consumer side and tacit collusion. European Economic Review, 49(2), 279-297.

Stahl, D. O. (1989). Oligopolistic pricing with sequential consumer search. The American Economic Review, 79(4), 700-712.

Stigler, G. J. (1961). The economics of information. Journal of Political Economy, 69(3), 213-25.

Stigler. G. J. (1964). A theory of oligopoly. Journal of political Economy, 72(1), 44-61.

Tirole, J. (1988). The Theory of Industrial Organization. MIT Press.

Wilkie, W. L. and Peter, R. D. (1991). Shopping for appliances: consumers' strategies and patterns of information search. Perspectives in Consumer Behavior. H. H. Kassargian and T.S. Robertson, eds., Englewood Cliffs, NJ: Prentice-Hall, 1-26.

Yeung, C. and Wyer, R. S. Jr. (2004). Affect, appraisal, and consumer judgment. Journal of Consumer Research, 31(9), 412-424. 